\title{
$\mathrm{R} C \& \mathrm{C}$
}

REVISTA DE CONTABILIDADE E CONTROLADORIA

\section{CONVERGÊNCIA AOS PADRÕES CONTÁBEIS INTERNACIONAIS: EVIDÊNCIAS EMPÍRICAS OBSERVADAS NO MERCADO DE CAPITAIS BRASILEIRO}

\section{Convergence process to International Financial Reporting Standards: empirical evidences in Brazilian Stock Market}

Recebido em 30.09.2014 | Aceite final em 27.08.2015 | Nota: este artigo foi aceito pelo Editor Jorge Eduardo Scarpin e passou por uma avaliação double blind review A reprodução dos artigos, total ou parcial, pode ser feita desde que citada a fonte.

Professora da Universidade Federal de Minas Gerais (UFMG)|Doutoranda em Controladoria e Contabilidade pela Universidade de São Paulo (FEA/USP)|Mestre em Controladoria e Contabilidade pela Universidade de São Paulo (FEA/USP)I Bacharel em Ciências Contábeis pela Universidade Federal de Minas Gerais (UFMG)|

\section{ESMAEL ALMEIDA MACHADO} Professor da Universidade Estadual do Mato Grosso do Sul (UEMS) | Doutor em Controladoria e Contabilidade pela Universidade de São Paulo (FEA/USP) | Mestre em Contabilidade pela Universidade Federal do Paraná (UFPR) | Bacharel em Ciências Contábeis pela Universidade Federal do Mato Grosso do Sul (UFMS) |

\section{GERLANDO AUGUSTO SAMPAIO FRANCO LIMA} Professor Doutor da Faculdade de Economia, Administração e Contabilidade da Universidade de São Paulo (FEA/USP) |

\section{RESUMO}

Apesar da transição compulsória das práticas locais de contabilidade para as IFRS (International Financial Reporting Standards) ter sido estabelecida para relatórios com data base de dezembro de 2010, uma parcela de empresas se antecipou a tal determinação. Diante desse cenário estabeleceu-se a seguinte questão de pesquisa: Quais fatores se relacionam com a divulgação voluntária de relatórios contábeis em consonância com as normas IFRS? Foi investigado como variáveis referentes à estrutura de capital, tamanho da empresa, governança corporativa e performance poderiam influenciar a decisão da empresa em adotar voluntariamente às IFRS. Os resultados demonstraram que empresas maiores e mais bem gerenciadas tenderiam a oferecer um nível de qualidade superior nas informações prestadas ao mercado, no que tange as demonstrações em 
IFRS. Além disso, encontraram-se evidências de que uma maior proporção de imobilizados influenciaria as empresas a adotarem às IFRS, na tentativa de demonstrar o real valor de suas propriedades.

Palavras-chave: Convergência de práticas contábeis; IFRS; Regressão Logistica; Adoção Voluntária.

\begin{abstract}
December, 2010 was set as the reference date for Brazilian' companies to move their financial statements to IFRS (International Financial Reporting Standards). However, we have observed that part of these companies has voluntarily anticipated such requirement. Thus, it seems relevant to establish the following question: Which factors can determine voluntary IFRS adoption? We have investigated how variables related to capital structure, company size, corporate governance and performance could influence the company's decision to voluntarily adopt IFRS. Our results have shown that larger firms and better managed ones tend to offer more information to the market. Furthermore, we have found evidences that, companies with a higher degree of properties tend to adopt IFRS, trying to demonstrate the real value of their properties to the market.
\end{abstract}

Keywords: Convergence of accounting standards; IFRS; Logit regression; Voluntary Adoption.

\title{
1 INTRODUÇÃO
}

O início do processo de convergência realizada na União Européia (UE) remonta ao final da década de 1970 sendo que, apenas em 2005, as empresas que estavam lá radicadas adotaram integralmente o International Financial Reporting Standards (IFRS). Entre os indutores da adesão, situaram-se a ampliação da integração econômica por meio de transações transfronteiriças e o respectivo crescimento no fluxo de capital, conforme indicam Renders e Gaeremynck (2007).

Entretanto, em outras partes do mundo, apesar de avanços semelhantes no nível de relações de negócio entre as nações, a convergência para as práticas contábeis promovidas pelo International Accounting Standards Board (IASB) está ainda em fase de implantação. Em tal conjuntura, encontram-se países como: Brasil, Japão, Índia e China. No Brasil, foi determinado que a obrigatoriedade da publicação das demonstrações contábeis pelas companhias abertas em full IFRS compulsoriamente seria a partir de 31 de dezembro de 2010(CPC 37, 2010). .

Conquanto, percebe-se que algumas empresas brasileiras anteciparam-se voluntariamente a exigência de publicar seus relatórios em full IFRS. Nesse sentido, cabe ressaltar o papel tanto a Comissão de Valores Mobiliários (CVM) quanto a Bolsa de Valores, Mercadorias e Futuros (BM\&FBovespa) que foram pioneiras na iniciativa de germinar entre as companhias de capital aberto radicadas no Brasil a adoção de padrões de contabilidade convergentes aqueles praticados sob a orientação do IASB.

Presume-se que a divulgação voluntária implantada seria um meio capaz de proporcionar benefícios imediatos para as companhias que assim o procedem, tais como redução em custos de transação em casos de captação de recursos no exterior. Aliás, Renders e Gaeremynck (2007) consideram que a redução de gastos com a conversão das demonstrações financeiras consiste em um fator 
preponderante na adoção das IFRS que por conseqüência, propicia ganhos no nível de transparência e comparabilidade para o mercado de capitais. Todavia, concomitantemente, há a incidência de gastos referentes à: i) implantação; ii) resultantes da ampliação da evidenciação contábil; e iii) redução/alteração das possibilidades de utilização dos métodos contábeis (RENDERS e GAEREMYNCK, 2007).

Considerando tais aspectos, mostra-se válido o questionamento acerca dos motivos que levam as empresas a optarem pela divulgação voluntária em full IFRS. Destarte, a sentença que expressa o problema da pesquisa é: Quais fatores se relacionam com a divulgação voluntária de relatórios contábeis em consonância com os padrões IFRS? Mudanças das práticas contábeis não podem ser consideradas a parte de outros elementos da infra-estrutura institucional, principalmente considerando que a convergência às normas internacionais de contabilidade tem permitido substancial discricionariedade por parte das empresas. Em suma, a maneira como as empresas empregam esta discricionariedade depende de seus incentivos subjacentes, assim como de suas características institucionais. Dessa maneira, estudos no sentido de identificar os incentivos econômicos à adoção das normas internacionais permitem uma análise - tanto em níveis médios quanto individuais - do seu grau de observância. Além disso, proporcionam um prognóstico inicial acerca do estágio atual do processo brasileiro de convergência contábil.

Uma série de estudos, principalmente na União Européia, foi conduzida na busca de se analisar os determinantes da adoção voluntária dos IFRS, adicionalmente aos padrões locais de Contabilidade. Evidências empíricas têm demonstrado uma influência positiva de fatores como tamanho, nível de internacionalização dentre outros na utilização das normas internacionais de contabilidade (GARCIA e ZORIO, 2002; CUIJPERS e BUIJIN, 2005; DEMARIA e DUFOR, 2007; RENDERS e GAEREMYNCK, 2007).

Todavia, certos fatores (e.g. sistema institucional, poder legal do enforcement, mecanismos dos mercados de capitais, estrutura de propriedade e características de governança corporativa) são, naturalmente, distintos entre os países, motivo pelo qual os incentivos para divulgação voluntária em IFRS podem não coincidir (LIMA et al., 2010). Ainda nesse sentido, observa-se que especificidades comuns a mercados emergentes podem levar a resultados discrepantes daqueles obtidos por pesquisas - já tradicionais - em mercados desenvolvidos. Dessa maneira, mostra-se relevante a análise do comportamento das empresas brasileiras frente à possibilidade de apresentação voluntária dos demonstrativos em padrões internacionais.

Neste contexto, a proposta em curso parte de uma análise cross-sectional dos dados como alternativa metodológica para responder a questão de pesquisa, servindo-se da aplicação de modelos de regressão logit. Na estruturação do artigo foram contempladas 5 seções, incluindo-se esta introdução. A seção 2 contém a plataforma teórica necessária à elaboração da resposta a questão de pesquisa. As técnicas de pesquisa, os instrumentos de coleta e as técnicas de análise de dados são evidenciados em seus pormenores na seção 3 , destinada a descrever os procedimentos metodológicos empregados. Na seção 4 os dados coletados são apresentados e, após analisadas as informações, são envidados esforços para permitir que a discussão dos resultados viabilize apresentar, na seção 5 , as considerações finais como resposta ao problema de pesquisa.

\section{PLATAFÓRMA TEÓRICA}

Nesta seção busca-se apresentar aspectos inerentes a convergência das práticas contábeis brasileiras para um padrão internacionalmente aceito. Nesse sentido, a discussão em tela tem a intenção de expor um mapa global para representar o estágio em que se encontram os países quanto à adoção do IFRS. Todavia, foi reservado espaço para o tema central, dedicado a apresentação de pesquisas 
anteriores que serviram de respaldo para condução da investigação em curso de maneira a contribuir para formulação da estratégia metodológica.

\subsection{A CONVERGÊNCIA INTERNACIONAL PARA PADRÕES CONTÁBEIS DO IASB}

A ausência de um padrão de práticas de contabilidade uniforme entre os países traz prejuízos na comparabilidade das informações presentes nos relatórios contábeis (LEMES e CARVALHO, 2004; KIRCHNER e OTT, 2005), fato que tornou imperativa a busca pela convergência a um padrão contábil internacional (EL HAJJ e LISBOA, 2001). Entre os beneficiados nesse processo, situam-se os agentes econômicos que necessitem tomar decisões econômico-financeiras, viabilizando uma avaliação parametrizada dos relatórios financeiros (WEFFORT, 2005).

Para o IASB o estabelecimento de bases comuns para a apresentação das demonstrações contábeis entre os países tem reflexo na ampliação do acesso ao capital internacional a custos inferiores aos praticados sem a convergência. Neste sentido, o IASB expressa que seu objetivo na condução desse processo é "prover a interação dos mercados de capitais de todo o mundo com uma linguagem comum para relatórios financeiros" (IASB, 2008, p.1).

Consoante a essa meta, a KMPG (2010) destaca que mais de 7 mil empresas realizaram a publicação de suas demonstrações contábeis no padrão IFRS em 2008. Atualmente o processo encontra-se em curso em mais de 100 países (SANTOS e CALIXTO, 2010). O mapa englobando todos os países, conforme sua situação em relação a adoção do IFRS encontra-se representado na Figura 1.

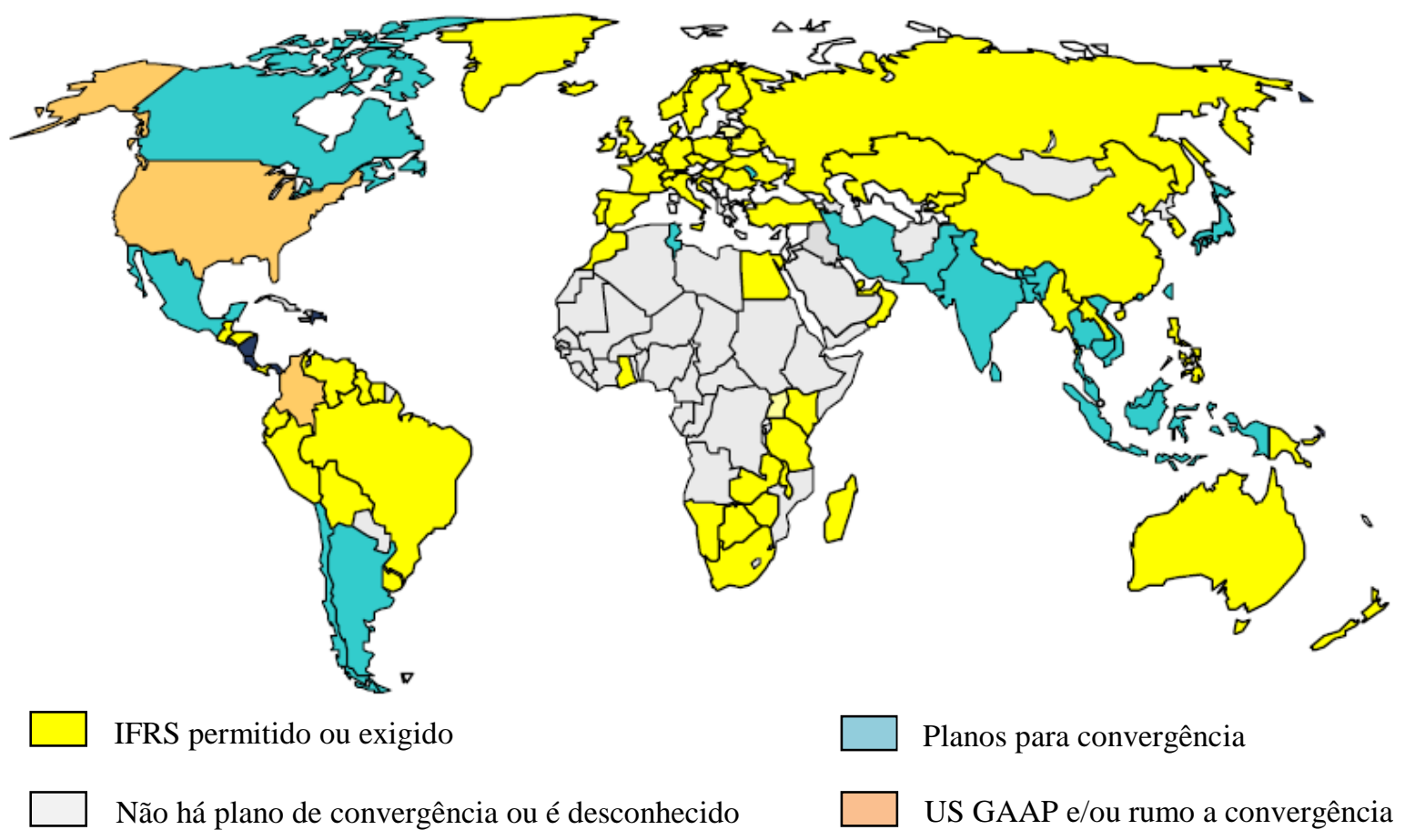

Mapa situacional da convergência às práticas contábeis estabelecidas pelo IASB

Fonte: KPMG, 2010

No Brasil, a convergência tem sido gradativa, com uma posição mais enfática a partir da alteração da lei societária no ano de 2007, responsável pela instituição do Comitê de Pronunciamentos Contábeis (CPC) como órgão responsável por orientar as práticas de contabilidade. A partir de então, ampliou- 
se a instrução de práticas contábeis em conformidade com os parâmetros do IASB e, que na prática, são equivalentes aos IFRS.

\subsection{ADOÇÃO VOLUNTÁRIA DAS IFRS: EVIDÊNCIAS EMPÍRICAS}

Dentre as metodologias disponíveis para a análise dos efeitos da adoção do IFRS, Gozáles et al. (2008) afirmam que a análise cross-sectional com apoio de modelos, tais como o logit, figuram dentre as técnicas mais utilizadas. Tais modelos são identificados como facilitadores para identificação de possíveis razões implícitas na adoção voluntária do IFRS bem como em estudos com enfoque em eventuais diferenças entre o padrão estabelecido pelo IASB e as práticas contábeis ainda em vigor em países não signatários da convergência.

Nessa perspectiva, Garcia e Zorio (2002) realizaram um estudo empírico que apontou evidencias quanto aos fatores que levaram empresas européias a aplicarem as normas de contabilidade internacional de maneira voluntária. Valendo-se do modelo logit, os autores analisaram uma amostra composta por 112 firmas daquele continente que procederam a essa opção. Como resultado, os autores observaram que o nível de internacionalização voluntária em termos de normas IFRS foi influenciado pelo tamanho e rentabilidade das empresas, além da reputação do auditor.

Cuijpers and Buijink (2005),por sua vez, investigaram determinantes da adoção voluntária de padrões contábeis não locais pelas firmas listadas e domiciliadas na União Européia. Os autores se restringiram na análise em dois padrões de Contabilidade: o International Accounting Standards (IAS) e o United States generally accepted accounting principles (U.S. GAAP). Os demonstrativos de 1999 foram analisados, para evitar que as escolhas dos métodos contábeis pelas companhias fossem influenciados pelo anúncio da Comissão Européia realizada em 2001, no qual ficou determinada a aplicação obrigatória às normas IFRS em 2005. Foram encontradas 133 empresas não-financeiras que publicaram voluntariamente em um padrão de contabilidade adicional ao local. A análise dessas 133 demonstrou a probabilidade de divulgação de demonstrativos em padrões não-locais é maior entre empresas com dispersão geográfica de suas operações, considerando aquelas listadas na bolsa européia EASDAQ (atual NASDAQ Européia) . Além disso, essas empresas, em geral, eram domiciliadas em países com qualidade inferior de demonstrativos contábeis, e nos quais,os padrões IAS eram explicitamente permitidos como uma alternativa aos padrões locais.

Demaria e Dufor (2007) analisaram a primeira adoção das normas IFRS, mais especificamente, a adoção voluntária de normas referentes ao conceito de valor justo (IFRS 1, IAS 16, 38 e 40), dentro da perspectiva da Teoria das Escolhas Contábeis. Da amostra inicial de 120 empresas componentes do índice Société des Bourses Françaises (SBF), foram excluídas empresas com dados faltantes ou aquelas que haviam exercido a opção em aplicar o IFRS em períodos anteriores ao período em análise. Após o filtro, a amostra considerada foi de 107 empresas. Além de uma visão qualitativa das possíveis escolhas contábeis na primeira adoção do IFRS pelas empresas francesas, os autores analisaram os determinantes dessas escolhas.

No trabalho daqueles autores, a Teoria Positiva da Contabilidade (PAT) - que encontra como um dos seus principais fundamentos à busca pela explicação das escolhas contábeis - foi utilizada como background. As escolhas contábeis foram relacionadas com características da empresa, tais como: tamanho, alavancagem, remuneração do CEO (Chief Executive Officer), estrutura de propriedade, participação da empresa em outros mercados financeiros e setor de atividade.

Partindo destas variáveis, o modelo de regressão logístico foi utilizado para determinar os fatores que influenciaram a adoção do fair value. Os resultados demonstraram que, para as empresas francesas da amostra, a escolha pelo fair value não se mostrou relacionado com tamanho, alavancagem financeira, remuneração dos CEO's, estrutura de propriedade e participação da 
empresa em outros mercados financeiros. De posse desses resultados, Demaria e Dufor (2007) concluíram que a PAT não foi suficiente para explicar as escolhas contábeis das empresas francesas na fase de primeira adoção do IFRS.

Outro estudo que se utilizou do modelo logístico para investigar os determinantes da adoção antecipada do IFRS foi o realizado por Renders e Gaeremynck (2007). A amostra foi composta por todas as empresas européias listadas em países que permitiam em 2001 a escolha entre os padrões locais ou o IFRS, determinando a seleção dos seguintes países: Áustria, Bélgica, Dinamarca, França, Alemanha, Itália e Países Baixos. A amostra final analisada pelos autores foi composta por 1.563 companhias, das quais 110 voluntariamente divulgaram suas informações segundo o padrão IFRS.

Neste estudo, Renders e Gaeremynck (2007) incluíram variáveis para controlar características específicas das empresas, tais como o nível de governança corporativa, distância entre os padrões locais e o IFRS, patamar de gerenciamento de resultados e tamanho do mercado de capitais. Além disso, foram incluídas variáveis para controlar características específicas das firmas. Os autores detectaram que países com leis mais severas ou regulamentos mais extensos de Governança Corporativa apresentam maior probabilidade de adotar as normas IFRS uma vez que a perda de benefícios privados dos insiders são inferiores. Adicionalmente, foi encontrado que as recomendações de governança corporativa são tão efetivas quanto às leis, estimulando a adoção do IFRS e mostrando-se ainda mais efetivas em países com leis menos rigorosas.

Os determinantes econômicos da adoção voluntária do IFRS no Brasil foram alvo da pesquisa de Lima et al (2010). Os autores analisaram como incentivos econômicos (tamanho, exposição ao mercado internacional, necessidade de financiamento e oportunidades de crescimento) afetavam o processo de convergência. Partindo de uma amostra cross-sectional composta por 50 empresas componentes do Índice Bovespa, os autores analisaram os relatórios anuais de 2008, data do início obrigatório da aplicação das atualizações da legislação societária visando à convergência ao padrão internacional do IASB. Os resultados demonstram que empresas de maior porte, com maior exposição ao mercado internacional e com maiores necessidades de financiamento apresentam maior propensão a adotar os novos dispositivos, apresentando mudanças materiais nas suas políticas contábeis, em relação àquelas que não possuem os mesmos incentivos.

\section{ABORDAGEM METODOLÓGICA}

\subsection{CRITÉRIOS PARA SELEÇÃO DA AMOSTRA}

A amostra inicial foi constituída por empresas componentes do Índice Brasil - IBrX elaborado pela BM\&FBovespa. O IBrX é um indicador que representa uma carteira teórica composta por 100 ações dentre as mais negociadas na bolsa de valores brasileira, tanto em termos de número de negócios, quanto de volume financeiro (BM\&FBOVESPA, 2010). Entretanto, visto a ocorrência de empresas com duas ou mais ações participando concomitantemente no indicador, foram filtradas 92 firmas.

Desse universo, foram excluídas oito empresas da área financeira. Isto porque, a inclusão de referidas empresas criaria obstáculos para fins de comparação, dado as especificidades do segmento de atuação, além de peculiaridades de seus demonstrativos financeiros (que adotam além das recomendações da Comissão de Valores Mobiliários, procedimentos mais específicos determinados pelo Banco Central).

O último filtro aplicado excluiu empresas que apresentavam informações contábeis incompletas (tais como ativo total, receita total e patrimônio líquido) para o trimestre analisado (segundo trimestre de 2010), determinando, então, uma amostra final de 78 empresas. As informações financeiras empregadas no estudo foram obtidas por intermédio da base de dados Economática ${ }^{\circledR}$, corrigidas $^{2}$ 
com o índice IPCA (Índice de Preços do Consumidor Amplo) pela inflação acumulada até 30/06/2010 e trabalhadas estatisticamente no Software EVIEWS 5.

\subsection{MODELO DE REGRESSÃO COM VARIÁVEL DEPENDENTE QUALITATIVA}

Com o intuito de analisar as características que influenciaram na decisão das empresas da amostra em adotar voluntaria e integralmente o IFRS foi utilizado um modelo de regressão em que a variável dependente é qualitativa. Tal modelo permite ao pesquisador analisar o efeito de cada variável explanatória sobre a probabilidade de um evento ocorrer (LUCCHESI, 2010).

O modelo de regressão selecionado para estimar a probabilidade de a empresa optar entre as possibilidades existentes (antecipar ou não a adoção do IFRS) é a regressão logística (logistic regression), também conhecida como modelo logit. Para Hair Jr. et al. (2005), a regressão logística é apropriada quando a variável dependente é categórica (nominal ou não métrica) e as variáveis independentes são métricas ou não métricas.

Além do modelo logit, dois modelos alternativos são empregados com recorrência: o modelo de probabilidade linear e o modelo probit. $O$ modelo de probabilidade linear é afetado por uma série de problemas tais como: suposição de normalidade e homocedasticidade dos resíduos, possibilidade de que o valor estimado da variável dependente se situe fora da faixa 0-1, além de valores de R2 sem poder de explicação. Adicionalmente, o modelo pressupõe que mudanças na variável independente afetam linearmente a variável dependente. Nesse sentido, o modelo de regressão logística incorpora efeitos não lineares, bem como não permite que os valores estimados da variável dependente situem-se fora do intervalo 0-1. Adicionalmente, a aplicação desse modelo justifica-se por sua qualidade de dispor medidas de diagnóstico, o que enseja em sua similaridade de interpretação, comparativamente a regressão linear tradicional (GUJARATI, 2006).

\subsection{DEFINIÇÃO OPERACIONAL DAS VARIÁVEIS \\ 3.3.1 TAMANHO DA EMPRESA - LN_VM}

Para controlar o tamanho da companhia utilizou-se uma proxy calculada a partir do logaritmo natural do seu valor de mercado. A relação entre divulgação voluntária de informações e o tamanho da empresa se baseia na expectativa de que os custos referentes à divulgação de informações sejam inferiores em empresas de maior porte.

Lang e Lundholm (1993) ressaltam que, embora não haja uma razão explicita para a associação entre os custos de divulgação de informações e tamanho da empresa (pelo contrário, os custos totais de divulgação tendem a ser maiores em empresas de grande porte) há provavelmente um componente fixo nos custos de evidenciação. Por conseguinte, o custo unitário da produção e divulgação de informações reduz-se à medida que o rol de informações apresentadas ao mercado aumenta o que leva a empresas maiores, com maior montante de recursos disponíveis a divulgarem uma maior quantidade de informações. Além disso, Meek e Roberts (1995) apresentam a hipótese de que empresas de grande porte podem apresentar menores custos de uma possível desvantagem competitiva relacionada a seu disclosure. 


\subsubsection{EMPRESA DE AUDITORIA - BIG_FOUR}

Outra influência analisada foi a da presença de uma das quatro maiores empresas de auditoria - big four (KPMG, Deloitte, Price e Ernst Young) como responsável pelos trabalhos de auditoria externa. Neste aspecto, assume-se que tais empresas de auditoria, dado seu porte e experiência na aplicação do IFRS, podem estimular as companhias a adotarem integral e voluntariamente o IFRS na elaboração de suas demonstrações contábeis (RENDERS e GAEREMYNCK, 2007).

\subsubsection{IMOBILIZAÇÃO DO ATIVO - IMOB}

Dye (1986) apud Renders e Gaeremynck (2007) afirma que a probabilidade do disclosure é reduzido a medida que os custos das propriedades se elevam. Adotando o IFRS, companhias revelam mais informações de suas propriedades. Neste sentido, entende-se que quanto maior o nível de recursos da companhia estiver investido em seu ativo imobilizado, menor será a tendência de que ela venha a adotar voluntária e integralmente o IFRS como padrão contábil para reporte de suas demonstrações contábeis (RENDERS e GAEREMYNCK, 2007).

\subsubsection{ALAVANCAGEM - ALAVAN}

De acordo com Lanzana (2004), companhias com elevado patamar de endividamento tendem a demonstrar um maior nível de disclosure de suas informações influenciado pela necessidade de prestação de contas aos seus credores. Isso porque, esses tendem a monitorar fortemente a gerência e demandar uma série de dados para garantir que a firma seja capaz de saldar suas dívidas.

Assim, espera-se que quanto maior o índice de alavancagem, maior a probabilidade de a empresa fornecer informações adicionais, tais como as demonstrações em consonância com as normas internacionais de Contabilidade (IFRS). Destaca-se que a variável "alavancagem"é o quociente resultante da divisão entre a dívida bruta e total do passivo.

\subsubsection{AMERICAN DEPOSITARY RECEIPTS - ADR}

Recentemente, a Securities and Exchange Commission (SEC) passou a permitir que empresas que negociam American Depositary Receipts (ADRs) na Bolsa de Nova lorque divulguem seus demonstrativos contábeis em IFRS, sem a necessidade da respectiva reconciliação para os US GAAP. (SANTOS e COSTA, 2008).

Como efeito dessa oportunidade dada à companhia - de livre arbítrio sobre o padrão contábil utilizado para reportar seus demonstrativos financeiros - sua decisão pode ser influenciada, tangendo a uma adoção full IFRS, antes mesmo da obrigatoriedade posta pela norma brasileira. Dessa maneira, ADR é um variável que indica 1 qual a firma em questão possui ADRs listadas no mercado americano e 0 caso contrário.

\subsubsection{MEDIDAS DE PERFORMANCE - MKBV E LPA}

Além disso, duas medidas adicionais de performance foram utilizadas: market-to-book-value(MTBV) e lucro por ação (LPA). A razão entre o valor de mercado de uma empresa e seu valor patrimonial (valor de livro) é comumente denominada na literatura como Market-to-Book (SANTANNA et al., 2003). Quando essa relação encontra-se em um patamar superior a uma unidade significa que o mercado reconhece em relação ao valor registrado nos livros contábeis, há indícios de que o 
mercado está valorizando algo que a contabilidade não mensurou, ou o fez, mas de maneira ineficiente. Quando a razão é menor do que a unidade, presume-se o inverso, ou seja, que o mercado não está reconhecendo valores (ou parcela dos mesmos) contabilizados pela companhia.

O LPA é um indicador financeiro que explicita a relação entre o lucro líquido da companhia, em um determinado período de tempo, e o seu número de ações. Assim, esse quociente é capaz de representar o montante em dinheiro gerado no lucro (ou prejuízo) para cada ação emitida. Tem-se que empresas lucrativas (que apresentam um índice de lucro por ação elevado) ou que apresentam um índice MTBV alto tendem a se distinguir das firmas menos lucrativas de maneira a serem mais bem avaliadas, aumentando o aporte de capital dos investidores. Dessa maneira, tais empresas apresentariam um maior nível de disclosure voluntário, visando evidenciar sua situação ao mercado (RENDERS e GAEREMYNCK, 2007).

\subsubsection{MEDIDAS DE GOVERNANÇA CORPORATIVA - NOVO_MER E PREM}

A teoria de agência de Jensen e Meckling (1976) prediz que quanto maior a quantidade de mecanismos internos de controle (tais como o conselho de administração e o comitê de auditoria), maior nível de monitoramento na companhia, reduzindo assim, a assimetria informacional e o risco de comportamentos oportunos, conseqüentemente, induzindo a um maior nível de transparência. Assim, de acordo com Lanzana et al. (2006), em um ambiente de intenso monitoramento e alta governança corporativa esperar-se-ia que os agentes não dispusessem de nenhum tipo de incentivos para reter informações, levando a um aumento no nível de disclosure e aumento na qualidade das demonstrações contábeis. Para fins desse estudo, portanto, espera-se que quanto maior o nível de governança, maiores seriam os estímulos para a adoção voluntária das IFRS por parte das firmas.

Como proxy para medir o nível da governança corporativa das empresas, utilizou-se o Prêmio Investor Relations Global Rankings. O IR Global Rankings ("IRGR") é sistema abrangente de classificação para investidores, relatórios anuais online, práticas de governança corporativa e de disclosure de informações financeiras. O ranking é baseado em uma pesquisa técnica sobre as empresas de capital aberto. Desse modo, o recebimento de referido prêmio de governança foi considerado como um indicador de boa governança corporativa (IRGR, 2010).

Outra proxy empregada para mensurar um bom nível de Governaça Corporativa foi o fato das empresas pertencerem ao Novo Mercado (BM\&Fbovespa). De acordo com Andrade e Rossetti (2007), a constituição do Novo Mercado (NM) faz parte de uma série de iniciativas objetivando uma melhoria dos padrões de governança das empresas brasileiras. Atualmente, as empresas que recorrem a captação de recursos por intermédio do lançamento de Initial Public Offerings (IPO) ficam condicionadas a participar do NM, requerendo compromissos adicionais para assegurar um maior nível de governança.

De posse destes elementos, é apresentada a seguir uma visão global das características que foram consideradas como variáveis explanatórias do estudo, relacionando-as com a relação esperada entre as proxies e a opção da empresa quanto a adoção integral e voluntária do IFRS (QUADRO 1). 
Quadro 1 - Variáveis Explanatórias

\begin{tabular}{|l|l|c|}
\hline \multicolumn{1}{|c|}{ Variável } & \multicolumn{1}{c|}{ Proxies } & $\begin{array}{c}\text { Sinal } \\
\text { Esperado }\end{array}$ \\
\hline Tamanho & Tamanho da companhia (logaritmo natural do valor de mercado total) & + \\
\hline Auditor & 1 se a companhia for auditada por uma das Big-Four e 0 caso contrário & + \\
\hline Imob_Capital & Índice referente ao imobilizado sobre o total do PL (segundo semestre/2010) & - \\
\hline Alancagem & Alavancagem Financeira: Total de dívidas sobre o Patrimônio Líquido & + \\
\hline LPA & Lucro dividido pelo total de ações & + \\
\hline MTBV & Cociente entre o valor de mercado e o valor de livro (Patrimônio Líquido) & + \\
\hline ADR & Se a empresa negocia ADR & + \\
\hline Novo_mercado & Se a empresa negocia no novo mercado & + \\
\hline Gov_dif & Se a empresa recebeu o prêmio de governança corporativa. & + \\
\hline
\end{tabular}

Destarte, conforme descrito no quadro 1 , o sinal positivo corresponde a uma associação positiva entre tais características e a uma estratégia contábil que estimula a adoção do IFRS.

\section{APRESENTAÇÃO DOS DADOS E DISCUSSÃO DAS INFORMAÇÕES}

\subsection{ANÁLISE DESCRITIVA}

Dado a natureza da amostra - empresas componentes de um indicador que retrata as ações mais negociadas no mercado brasileiro ( $\mathrm{IBrX}$ ) -a média geral do valor de mercado das empresas analisadas, consoante as expectativas, foi de cerca de 1,6 bilhões de reais, enquanto a mediana manteve-se no patamar de $\mathrm{R} \$ \mathbf{7 , 4}$ bilhões. No limite inferior, situou-se a Kepler Weber, companhia do ramo da siderurgia e metalurgia, com valor de mercado de $\mathrm{R} \$ 444.895$ milhões. Por outro lado, a Petrobrás ocupa o extremo oposto, constando com valor de mercado superior a R\$256 bilhões.

Tabela 1 - Estatísticas Descritivas

\begin{tabular}{lccccc}
\hline & Média & Mediana & Desvio Padrão & Mínimo & Máximo \\
\hline IFRS & 0.167 & 0.00 & 0.375 & 0.00 & 1.00 \\
Ln do Valor de Mercado & 15.81 & 15.82 & 1.20 & 13.01 & 19.36 \\
Big Four & 0.86 & 1.00 & 0.35 & 0.00 & 1.00 \\
Imobilização do ativoAFx/PL & 98.19 & 79.00 & 114.25 & 0.20 & 925.20 \\
Alavancagem (DivBr/Patr) & 55.97 & 41.00 & 178.31 & -1081.50 & 692.50 \\
LPA & 0.45 & 0.29 & 0.61 & -1.03 & 2.78 \\
Market to book & 3.47 & 1.97 & 4.34 & 0.36 & 22.78 \\
Adr? & 0.64 & 1.00 & 0.48 & 0.00 & 1.00 \\
Novo Mercado? & 0.53 & 1.00 & 0.50 & 0.00 & 1.00 \\
Prêmio de Governança & 0.12 & 0.00 & 0.32 & 0.00 & 1.00 \\
Valor de Mercado (em milhares) & 1.6945 .039 & 7.392 .470 & 38.700 .187 & 444.895 & 256.675 .338 \\
\hline
\end{tabular}

Com relação a variável "Adoção d IFRS", observa-se que a parcela de companhias que seguiram essa posição voluntariamente foi inferior as demais. Em termos absolutos, 13 empresas optaram voluntariamente pela adoção. Outro fato que merece destaque, diz respeito à atuação das empresas 
de auditoria big four, na qual, em termos absolutos, demonstra que 67 das companhias que compõe a amostra foram auditadas por uma das quatro empresas categorizadas pela variável.

No que tange a variável "alavancagem" - obtida pelo quociente entre a dívida bruta e o patrimônio líquido - destaca-se que a amplitude mostrou-se em 1.774 pontos percentuais, nível considerado elevado. Não menos relevante foi a variabilidade dos dados referentes à imobilização do ativo, apesar de inferior ao percebido para a variável "alavancagem", essa medida registrou uma amplitude de 925 pontos percentuais.

\subsection{ANÁLISE INFERENCIAL}

A matriz de correlação de Pearson foi elaborada na intenção de que se obtivessem indícios quanto à direção das relações entre as variáveis e, principalmente, identificar a presença de significância estatística, considerando a expectativa de inferências com $p$-value $\leq 0,05$. Nestes termos, a Tabela 2 é apresentada a seguir.

Tabela 2 - Matriz de Correlação de Pearson

\begin{tabular}{|c|c|c|c|c|c|c|c|c|c|c|}
\hline & & & & & & & mkt_boo & & novo_m & \\
\hline & ifrs & In_vm & big_four & Imob & alavan & Lpa & k & $a d r$ & $r$ & Prem \\
\hline Ifrs & 1.000 & & & & & & & & & \\
\hline In_vm & $0,226^{* *}$ & 1.000 & & & & & & & & \\
\hline big_four & 0.094 & 0.177 & 1.000 & & & & & & & \\
\hline Imob & 0.153 & 0.064 & $0.197 *$ & 1.000 & & & & & & \\
\hline Alavan & 0.137 & $\begin{array}{l}-0.176^{*} \\
0,425^{* *}\end{array}$ & 0.042 & $0,497 * * *$ & 1.000 & & & & & \\
\hline $\begin{array}{l}\text { Lpa } \\
\text { mkt_boo }\end{array}$ & $\begin{array}{l}0.049 \\
0,360^{* *}\end{array}$ & $*$ & $0.191^{*}$ & -0.107 & -0.123 & 1.000 & & & & \\
\hline $\mathrm{k}^{-}$ & $*$ & 0.135 & 0.181 & -0.020 & $0,243^{* *}$ & -0.073 & 1.000 & 1.00 & & \\
\hline Adr & 0.071 & 0.206 & -0.150 & 0.061 & $0.194 *$ & $\begin{array}{l}-0.122 \\
-\end{array}$ & 0.047 & 0 & & \\
\hline novo_me & & & - & - & & 0.212 & & 0.09 & & \\
\hline r & -0.024 & $-0,250^{* *}$ & $0,311^{* * *}$ & $0,299 * * *$ & 0.015 & $*$ & 0.137 & $\begin{array}{l}2 \\
0.18\end{array}$ & 1.000 & \\
\hline Prem & 0.040 & $0.214^{*}$ & $-0.200 *$ & -0.039 & -0.018 & 0.071 & -0.115 & 7 & 0.182 & 1.000 \\
\hline
\end{tabular}

* significativa ao nível de $10 \%$

** significativa ao nível de $5 \%$

$* * *$ significativa ao nível de $1 \%$

Os resultados em tela indicam uma correlação entre o valor de mercado e a adoção ou não do IFRS, com significância estatística a um nível de $95 \%$ de confiança. Em termos mais robustos, observa-se que a correlação entre a variável que controla a adoção ou não do IFRS e o MTBV alcançou um nível de significância estatística de $99 \%$ de confiança, projetando um coeficiente de 0,36 entre as duas variáveis.

Partindo dessas constatações, encontram-se indícios de que quanto maior o tamanho da companhia, e que, quanto melhor for sua performance, maior será a probabilidade de que ela venha a adotar voluntária e integralmente o IFRS. Todavia, esses resultados são insuficientes para determinar em que intensidade essas variáveis podem, em conjunto ou separadamente, interferir na variável 
dependente analisada (IFRS), sendo úteis, entretanto, como ponto de partida da metodologia de análise de regressões.

Antes, porém, cabe mencionar que, excetuando-se os sinais referentes à Imobilização do Capital, os demais se apresentaram em conformidade com o esperado. Adicione-se a isso, o fato de que as correlações entre as variáveis explicativas, aquelas apresentaram maior coeficiente $(0,4789)$, com pvalue igual a 0,01. Na seqüência, as variáveis "lucro por ação" e "In_vm" alcançaram coeficiente de 0,425 ( $p$-value $=0,01$ ).

Sobre esses resultados, vale lembrar que a correlação entre as variáveis "Imobilização do Capital" e da "Alavancagem" possui explicação no fato de ambas compartilharem o mesmo denominador (Patrimônio Líquido) no cálculo de seus indicadores. No que tange a relação entre a variável "lucro por ação" e a variável "In_vm", tem-se que,apesar de In_vm ser um indicador capaz de mensurar o tamanho da companhia, o mesmo também demonstra a valorização da companhia frente a mercado (uma vez que o valor de mercado é o produto da quantidade de ações pelo valor das ações no mercado). Dessa maneira, dado a correlação significativa e positiva, pode-se inferir que o mercado confere valor superior às companhias que proporcionam maior remuneração aos acionistas.

Quanto ao nível de correlação entre as variáveis, os coeficientes não indicaram para a presença do problema econométrico de multicolinearidade. O modelo logístico foi estimado e, posteriormente, as variáveis não significativas foram excluídas, Ao realizar o teste de White a hipótese de homocedasticidade foi rejeitada (comportamento bastante comum em amostras de corte transversal). Dessa maneira a regressão foi re-estimada utilizando a variância e os erros-padrão consistentes para heterocedasticidade de White. O modelo final alcançado é exposto na Tabela 3.

Tabela 3-Output para o método Logit

\begin{tabular}{|c|c|c|c|c|}
\hline Variável & Coeficiente & Erro Padrão & Estatística - t & Prob. \\
\hline LN_VM & 0.519247 & 0.312899 & 1.659469 & 0.097 \\
\hline MKT_BOOK & 0.163608 & 0.064056 & 2.554145 & 0.010 \\
\hline C & -10.9277 & 5.082096 & -2.150234 & 0.031 \\
\hline IMOB & 0.003299 & 0.001653 & 1.995073 & 0.046 \\
\hline McFadden R-squared & 0.176531 & & & \\
\hline
\end{tabular}

Confirmando os indícios evidenciados após a análise da matriz de correlação, constatou-se que aquelas variáveis com os maiores níveis correlação, foram as selecionadas para compor o modelo de regressão, alcançando significância suficiente. Adicionalmente, a variável "imobilização do capital" foi considerada como relevante na composição do modelo. Ainda que não tenha apresentado níveis de correlação significativos, ela contribuiu para explicara adoção voluntária e antecipada do IFRS ( $p$ value $=0,046$ ).

A equação resultante do modelo exposto na Tabela 3 permite inferir que, com base no coeficiente da variável "In_vm", quanto maior a companhia, maior é a probabilidade de que ela faça opção pela adoção voluntária do IFRS para subsidiar a elaboração e publicação de suas demonstrações contábeis. A explicação proposta é de que, para tais empresas, o custo de divulgação de dados adicionais seria inferior, o que as tornaria mais propensas a aumentar o rol de informações oferecidas ao mercado (LANG e LUNDHOLM, 1993). Em complemento, essa maior propensão poderia ser influenciada pelo fato de que empresas de maior porte apresentariam menores custos de uma possível desvantagem competitiva relacionada a seu disclosure (MEEK e ROBERTS, 1995). 
Em conformidade com as expectativas, a variável "MTBV" apresentou o sinal esperado. Assim, infere-se que as companhias lucrativas que alcançam uma valoração superior aos olhos do mercado, buscam se diferenciar apresentando um maior nível de disclosure voluntário (RENDERS e GAEREMYNCK, 2007).

Entretanto ao contrário do esperado, a relação entre a variável "imobilização do capital" e a variável "IFRS" não apresentaram relação inversa. Esperar-se-ia que quanto maior a quantidade de propriedade por parte das empresas, mais informações as companhias deveriam revelar acerca de si e menor a probabilidade de adoção antecipada do IFRS. Uma explicação plausível para esse achado refere-se às possibilidades adicionais oferecidas pelo IFRS de contabilização dos ativos imobilizados. A Contabilidade brasileira baseada nas normas tributárias influenciava as empresas na adoção de taxas fiscais de depreciação e no registro de seus ativos pelo valor histórico. Com a transição para uma contabilidade baseada na primazia da essência sobre a forma as empresas passaram a ser estimuladas a registrar seus ativos levando-se em conta a realidade econômica. Dessa maneira, ao invés do esperado, as empresas com maior nível de imobilizado teriam um estímulo maior para preparar, antecipadamente, suas demonstrações contábeis sob a égide do IFRS, e assim, demonstrar aos usuários externos uma maior confiabilidade na mensuração do valor econômico de seus ativos.

Contrariamente ao esperado, a variável "auditor" não foi fator determinante na adoção do IFRS. A ausência de significância dessa variável pode ser justificada pela grande quantidade de empresas atendidas pelas mesmas. Como quase todas as empresas são auditadas pelas big four, esse não seria mais fator diferenciador das empresas. O mesmo pode ser observado com relação à variável ADR, 50 entre as 78 empresas emitem esse tipo de valor mobiliário. No caso da alavancagem, como dito anteriormente, houve um alto grau de variabilidade, o que reduziu a capacidade do modelo em captar um padrão entre as empresas que adotam o IFRS e as que não procederam a essa opção. Com relação à falta de significância das variáveis indicativas de governança corporativa, tem-se que tal fato não implica necessariamente em uma ausência de relação entre mecanismos de governança e a adoção voluntária do IFRS. Essa ausência de significância pode demonstrar a incapacidade das proxies adotadas captar o efeito desejado.

\section{CONSIDERAÇÕES FINAIS}

O objetivo da presente pesquisa consistiu em analisar a adoção antecipada do IFRS, a qual está relacionada com um aumento do nível de disclosure e a alteração/redução das escolhas contábeis. Neste cenário, considerou-se a associação entre as características específicas das empresas e sua disposição em reduzir seus níveis de informações privilegiadas. Para que o objetivo proposto fosse alcançado, analisou-se uma amostra composta por 78 empresas não financeiras componentes do Índice Brasil (indicador que retrata o comportamento das principais ações negociadas no Brasil $\mathrm{IBrX}$. O modelo empregado para a análise das relações foi o modelo logístico, que permite captar a probabilidade de ocorrência do evento analisado.

Por intermédio da análise de regressão foi possível inferir que três variáveis foram estatisticamente significativas na tarefa de explicar a adoção inicial voluntária dos padrões internacionais de contabilidade. A primeira, o tamanho, demonstrou que quanto maior o tamanho da empresa, menor seria o custo unitário da informação e menor seria também o custo relacionado à desvantagem competitiva de um disclosure adicional, levando a uma maior probabilidade em adotar voluntariamente o IFRS.

Uma segunda variável foi referente ao indicador market to book. Uma maior a relação entre o valor de mercado e o valor patrimonial descrito nos livros contábeis demonstra uma boa valorização da companhia por parte do mercado, o que demonstra que a empresa possui mecanismos adicionais, 
tais como um maior nível de evidenciação, para garantir esse nível de valorização, proporcionando assim uma maior quantidade de aportes de capital.

Por último, o nível de imobilização apresentou uma relação inversa à probabilidade de a empresa adotar voluntariamente o IFRS. Assim, como o resultado apresentou direção contrária à esperada, especulou-se que a transição ao IFRS tem permitido um aumento de discricionariedade da contabilização do valor dos imobilizados, migrando a contabilidade brasileira de um regime baseado em normas para um regime baseado em princípios. Conseqüentemente, quanto maior as propriedades da empresa, mais estímulos a mesma teria em adotar as novas normas e assim apresentar aos seus shareholders e stakeholders uma contabilidade mais próxima a realidade de seu negócio.

Como limitação da pesquisa encontra-se o fato de que a amostra selecionou de maneira nãoprobabilística empresas os componentes do indicador IBrX, que engloba em geral empresas de grande porte, fato que impede a generalização dos resultados. Dentre as possibilidades para futuras pesquisas, encontra-se a análise da reação do mercado frente à adoção dos IFRS's por parte das companhias. A aplicação do IFRS pode resultar em uma reação (i) positiva (ii) negativa ou (iii) neutra por parte dos investidores dependendo de suas expectativa acerca da mudança no nível de qualidade das informações contábeis. A identificação de anormalidades do mercado frente à adoção voluntária do IFRS torna possível a análise do impacto da adoção das práticas contábeis do IFRS na qualidade e comparabilidade das informações financeiras divulgadas pelas companhias e de como a mesma pode influenciara visão dos investidores acerca das companhias e suas potencialidades de rentabilidade futura.

Outra possibilidade para futuras pesquisas consiste em analisar não mais a adoção voluntária, mas a adoção mandatória, que passará a vigorar para as publicações reportadas a partir de janeiro do ano de 2011. A transição dos padrões contábeis utilizados por todas as companhias com ações negociadas no mercado de ações brasileiro (BMF\&Bovespa) oferece uma oportunidade única para se analisar como essa transição afeta na compatibilidade, nível de conservadorismo e na qualidade da informação contábil divulgada.

\section{REFERÊNCIAS}

ANDRADE, A.; ROSSETTI, J. P. Governança Corporativa. São Paulo: Atlas, 2007.

IRGR, About IR Global Rankings, 2010. disponível em: <http://www.irglobalrankings.com/irgr2010/web/default_eni.asp?idioma=1\&conta=46>. consultado em: $12 /$ dez./2010

Comitê de Pronunciamentos Contábeis. Pronunciamento Técnico CPC 37, de 05 de Novembro de 2010. Adoção Inicial das Normas Internacionais de Contabilidade. Disponível em: http://www.cpc.org.br/pdf/CPC37_R1_final.pdf Acesso em 02 de janeiro de 2011.

CUIJPERS, R e BUIJINK, W. 2005. Voluntary adoption of non local GAAP in the European Union: a study of determinants and consequences. European Accounting Review. 14, 3, 487-524

DEMARIA, S. e DUFOR, D. First time adoption of FIRS, Fair Value Option, Conservatism: Evidence from French listed companies. Working paper, Nice Sophia Antipolis University.

EI HAJJ, Z. S.; LISBOA, L. P. Business combinatione Consolidação das Demonstrações Contábeis: Uma Abordagem Comparativa entre os Pronunciamentos e Normas dos USGAAP, IASC e Brasil. Revista de Contabilidade \& Finanças FEA USP. São Paulo. Ano XII, Vol. 16, Número 27, 33-58, set/dez. 2001. 
IASC e Brasil. Revista de Contabilidade \& Finanças FEA USP. São Paulo. Ano XII, Vol. 16, Número 27, 33-58, set/dez. 2001.

GONZÁLES, M. NAVE, J. PARTO, D. T. Quantifying Effects of Mandatory Adoption of IFRS: A Dynamic Accounting Model. Working paper, Universidad CEU Cardenal Herrera.

GUJARATI, D. Econometria Básica. Rio de Janeiro: Campus/Elsevier, 2006.

HAIR JR., Joseph F. et al.Análise multivariada de dados. 5. ed. Porto Alegre: Bookman, 2005.

IASB - International Accounting Standards Board. About us / Frequently Asked Questions /How is The IASB Structured? / IASB And The IASC Foundation, Who We Are AndWhat We Do. Disponível em: <www.iasb.org>. Acessoem 01/Nov./2010.

JENSEN, M. C.; MECKLING, W. Theory of the Firm: Managerial Behavior, Agency Costs and Capital Structure. Journal of Financial Economics, v. 3, 1976.

KPMG.IFRS Workshop: A visão de quem audita. Disponível em: < http://www.bndes.gov.br/SiteBNDES/export/sites/default/bndes_pt/Galerias/Arquivos/conheciment o/seminario/ifrs_kpmg.pdf>. Acesso em: 14/Nov./2010

KIRCHNER, A. E.; OTT, E. Aplicação das Normas Contábeis Brasileiras e Norte- Americanas: uma análise na conciliação da demonstração das diferenças no lucro líquido e do patrimônio líquido da AMBEV. In: V CONGRESSO USP DE CONTROLADORIA E CONTABILIDADE, 2005, São Paulo - SP. Anais... São Paulo: USP, 2005.

LANG, M.; R. LUNDHOLM Cross-sectional Determinants of Analyst Ratings of Corporate Disclosures, Journal of Accounting Research, 31(2), pp. 246-271, 1993.

LANZANA, A. P. Relação entre disclosure e governança corporativa das empresas brasileiras. 165 f. 2004. Dissertação (Mestrado em Administração) - Faculdade de Economia, Administração e Contabilidade da Universidade Federal de São Paulo (USP), 2004.

LANZANA, A. P.; SILVEIRA, A. M.; FAMÁ, R. Existe Relação entre Disclosure e Governança Corporativa no Brasil? In: Encontro da Associação Nacional dos Programas de pós-graduação em Administração. ENANPAD, 2006, Salvador-BA. Anais... Salvador, 2006.

LEMES, S.; CARVALHO, L. N. G. Efeito da Convergência das Normas Contábeis Brasileiras para as Normas Internacionais do IASB. In: IV CONGRESSO USP DE CONTROLADORIA E CONTABILIDADE, 2004, São Paulo - SP. Anais... São Paulo: USP, 2004.

GARCIA B., M. A.; ZORIO, A. 2002.Características de las empresas europeas que aplican las normas del IASC. Evidencia empírica de cara al debate regulado en la nueva fase de armonización contable. Revista Española de Financiación y Contabilidad XXXI, 111, 75-110

LIMA, V. S.; LIMA, G. A. S. F. ; LIMA, I. S.; CARVALHO, L. N. G. Determinantes da Convergência aos Padrões Internacionais no Brasil. In: IV Congresso ANPCONT, 2010, Natal. Anais... Natal: 2010.

LUCCHESI, E. P. O efeito disposição e suas motivações comportamentais: um estudo com base na atuação de gestores de fundos de investimento em ações. 178p. Tese (Doutorado) -

MEEK, G. K. ROBERTS, C. B. Factors Influencing Voluntary Annual Report Disclosures by U.S., U.K. and Continental European Multinational Corporations, Journal of International Business Studies, 26(3), pp. 555-573, 1995.

RENDERS, A.; GAEREMYNCK, A.The impact of legal and voluntary investor protection on the adoption of international financial reporting standards (IFRS).De Economist, v. 155, n. 1, p. 49-72, 2007. 
SANTANNA, D. P.; TEIXEIRA, A. J. C.; LOUZADA, L. C. A relação entre market-to-book equity e lucros anormais no mercado de capitais no Brasil. Anais... Enanapd 2003.

SANTOS, E. S.; CALIXTO, L. Impactos do início da harmonização contábil internacional (Lei 11.638/07) nos resultados das empresas abertas. RAE eletrônica, v. 9. N. 1, São Paulo, jan./jun., 2010.

SANTOS, L. S. R. dos e COSTA, F. M. da. Conservadorismo contábil e timeliness: evidências empíricas nas demonstrações contábeis de empresas Brasileiras com ADRs negociados na bolsa de Nova lorque. Revista contabilidade e Finanças [online]. 2008, vol.19, n.48. Disponível em: http://www.scielo.br/pdf/rcf/v19n48/v19n48a03.pdf. Acesso em 01/Dez./2010.

WEFFORT, Elionor Farah Jreige. O Brasil e a harmonização contábil internacional. São Paulo: Atlas, v. 140, 2005. 